\title{
Experimental Investigation of Propertiesand Sound Absorption Test on Reinforced Composite Material of Raw Palmyra Fiber
}

\section{Authors}

\author{
P.Nithyakalyani $^{1}$, N.Dhandapani ${ }^{2}$, A. Megalingam Murugan ${ }^{3}$ \\ ${ }^{1}$ PG Student, Department of Mechanical Engineering, Angel College of Engineering \&Technology, Tirupur \\ ${ }^{2}$ Assistant Professor, Department of Mechanical Engineering, Angel College of Engineering \&Technology, Tirupur \\ ${ }^{3}$ Associate Professor, Department of Mechanical Engineering, BIT, Sathy \\ Email- ${ }^{1}$ nithi.red@gmail.com, ${ }^{2}$ ndhandapanime@gmail.com, ${ }^{3}$ mechmega@gmail.com
}

\section{ABSTRACT}

Increasing concern about global warming and high intensity of sound has made scientists to focus more on the use of natural fibres such as coir, sisal, jute etc. This has resulted in creation of more awareness about the use of natural fibres based materials mainly composites. In past decennium there have been many efforts to develop composites to replace non decaying materials based products. The profuse availability of natural fibre in India gives attention on the development of natural fibre composites primarily to look at value-added application avenues. Reinforcement with natural fibre in composites has lately gained attention due to low cost, easy availability, acceptable specific properties, ease of severance, improved energy recovery, biodegradability and recyclable in nature. Palmyra fibre is one such type possessing high cellulose which is economical and available in plenty. The Palmyra fibres were extracted and its physical and chemical properties like density, cellulose, wax, moisture were experimentally determined. Also make a composite material using Epoxy Resin and to test the sound absorptionproperty.

Keywords- Palmyra fibre, Physical properties, Chemical properties, reinforced composite materials, Sound absorption.

\section{INTRODUCTION}

\subsection{Introduction of Fibre}

Over the past two decennium, polymer-based materials reinforced with various natural fibres have been established everywhere from scholastic and industrial point of view. Environmental consciousness, legislation, and energy consumption have enthused academics and industrial researchers working in the area of cellulose fibres and fibrereinforced composite. More than 1000 species of cellulose plants are being obtainable in fibres forms and few of them are investigated to plan the toughened composite. The natural fibre composites have attractive features likes low cost, light- in weight, moderated potency, high specific modulus, moderate mechanical properties, easy to handle, and lack of health hazards compared to synthetics fibrecomposite. Structure of the fibre is encased with natural chemicals such as cellulose, lignin, and wax. The cellulose fibre-reinforced composites have been extensively used for industrial components, construction material, automobile parts, and homeappliances.

In latest years, the interest of scientists and engineers has bowed over on utilizing plant fibres as efficiently and inexpensively as possible to produce good quality fibre- reinforced polymer composites for structural, building, and other needs.

Many types of natural fibres have been explored for their use in polymer like wood fibre (Maldas et al 1995), kenaffibre (Rowell et al 1999), pineapple fiber (Mishra et al 2001), sisal fiber (Joseph et al 1999) jute fiber (Mohantyet al 2006), banana fiber (Pothan et al 2003) and straw (Camel 2004).Bax and Mussig 2008 investigated the mechanical properties of PLA reinforced with cordenka rayon fibres and flax fibres, respectively.

A poor bond was observed using Scanning electron 
microscopy analysis. The highest impact strength and tensile strength were establish for cordenko reinforced PLA at fibre proportion of 30\%.Mwaikambo and Ansell 2003 evaluated the physical and mechanical properties of the natural fibre composites to review their serviceability. Treated fibres with highest might were used as reinforcement for cashew nut shell liquid matrix and determined tensile properties, porosity and also tested fracture surface topography of the composites. The objective was to maximize the amount of low cost natural fibre resource in the composite. They finished that the presence of lignin in the raw hemp fibre offers additional cross linking sites and the raw fibre surface is more compatible with CNSL (Cashew Nut Shell Liquid Resin) than alkali treated surface.

Natural fibres are consequent from plants, animals and mineral sources. They can be classified according to their origin as depicted. These of natural fibres as industrial components improves the environmental integrality of the parts being constructed, especially the moving market. In the building industry, the interest in natural fibres is mostly efficient and nominal; natural fibers allow insulation properties higher thancurrent materials. Presents few of the most used natural fibers, family name and scientific name. Although, the annual production of natural fibers exceed that of animal or mineral fibers, all have long been useful to human. The properties of natural fibers depend mainly on the nature of the plant, vicinity in which it is grown, age of the plant, and the dissociation method used (Joseph et al 1999, Khandal et al 2011 and Kuchinda et al 2001). The physical properties of natural fibers were mainly resolved by their chemical and physical composition, such as, structure of fibers, cellulose content, and angle of fibrils, transaction and degree of polymerization (Idicula et al2005).

\subsection{Introduction of CompositeMaterials}

The attention in natural fiber-reinforced polymer composite materials is hastily growing both in terms of their engineering applications and basic research.
They are sustainable, cheap, completely or partially recyclable, and biodegradable. Plants, for example flax, cotton, hemp, jute, sisal, kenaf, pineapple, ramie, bamboo, banana, etc., as well as wood, used from time primeval as a source of lignocelluloses fibers, are more and more often applied as the reinforcement of composites. Their accessibility, sustainability, low density, and price as well as satisfactory mechanical properties make them a striking environmental alternative to glass, carbon and man-made fibers used for the manufacturing of composites. The natural fiber-containing composites are more ecological friendly, and are used in transportation, military applications, civil application , packaging, consumer products,etc.

The word "composite" means two or more divergent parts physically bounded together". Thus, a material having two more distinct ingredient materials or phases may be considered a composite material. Fiber- reinforced composite materials contain fiber of high strength and modulus embedded in or bonded to a matrix with discrete interfaces (boundary) between them. In this form, both fiber and matrix keep their physical and chemical identity, yet they produce a combination of properties that cannot be achieved with either of the ingredient acting alone. In general, fiber are the principal load-carrying members, while the neighboring matrix keeps them in the preferred location and orientation, acts as a load transfer medium between them, and preserve them from environmental damages due to elevated temperatures and humidity etc.

The properties that can be enhanced by forming a composite material consist of strength, stiffness, corrosion resistance; wear resistance, pleasant appearance, weight, fatigue life, temperature-reliant behavior, thermal insulation, thermal conductivity, acoustical isolating and electrical isolating. Naturally, neither all of the properties are improved at the same time nor is there usually any necessity to do so. Composite materials have a long history of usage. Their beginnings are unheard of, but allrecorded history contains references to some form of composite material. For example, straw was used by the Israelites to toughen mud bricks. Plywood was 
used by the ancient Egyptians when they recognized that wood could be rearranged to achieve better strength and resistance to thermal expansion as well as to distension due to the presence of moisture. More recently, fiber reinforced resin composites that have high strength-to- weight and stiffness- toweight ratios have become significant in weightsensitive applications such as aircraft and space vehicles.

A variety of products around us are made from plastics. One of them is fiber-reinforced plastics (FRP). Advantages of FRP are that specific strength is superior than that of aluminumplate, and weight of FRP is lighter than that of aluminum plate, etc. Therefore, FRP are used in ample range of fields, for example, automobile field, aerospace field, games field, and so on. Glass-fiber reinforced plastic (GFRP) inside FRP has a lot of excellent functions such as high-strength, weightlessness and chemical stability. But, this GFRP has a serious environmental fault that disposal and recycling are tricky after usage there is an increase demand for environmental friendly materials such as natural fiber composites to replace the conventional fiber (i.e. carbon, glass, and aramid fiber) composites.

The reasons are biodegradability, less emissions to the atmosphere, plentiful, renewable, userfriendliness, and can be produced at low cost in many parts of the developing world. Recently there is study of "green" composites (the biodegradable composite materials or eco-composites).

Composed of a eco-friendly resin and high strength natural fibers have been developed. Advantages of natural fiber are low heaviness, they are recyclable and ecological. They are also renewable and have relatively high strength and stiffness. On the other part, there are also some disadvantages: moisture uptake, quality variations and thermal stability. And in actual fact, the mechanical property of natural fiber was much more inferior to that of glass fiber. Therefore, necessary functional strength for structural materials or upgrading of strength and toughness ofgree composites and securement of dependability are not enough. Because it is necessary that the mechanical property of natural fiber move toward that of glass fiber, and natural fiber have the electivefunctions.

\section{MATERIALS ANDEXPERIMENTS}

\subsection{Extraction of Fibre}

Palmyra fiber is a natural fiber that derives from treatment of the leaf seats of the Palmyra Palm and is produced. The matured Palmyra were collected from Palmyra trees and immersed in water for two days. The flush which was bonded with the fibers absorb water and the steep of the same started. The flush lost its bonding strength at this stage.

Now the leaf stems were taken out of water and thoroughly washed in running water. During the washing process the leaf stems were gently pressed for the removal of the retted flush. The leaf stems were then immersed in water for one day and the process was repeated for the removal of remaining flush. The fibers were taken out and allowed to dry in the shadow for a pair of days. The fibers were then dried in sunlight for half an hour andextracted.

Fiber is available in the form of stalk on a Palmyra tree. First collect dried bracts from the Palmyra tree then after segregate fibers from the stalk then after Fibers are cleaned and dried under sun for two days to remove moisture content. Further, the fibers were kept in oven for 120 minutes at $700 \mathrm{C}$ to ensure that maximum moisture was removed. The above fibers extricated by different methods are used for making composite specimens and tested as per ASTM standards.
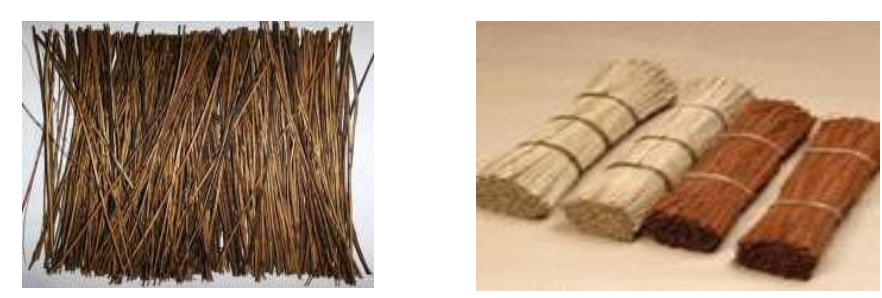

Fig.1 Raw Palmyra fiber

\subsection{Fibre Properties}

\subsubsection{FiberDensity}

The water displacement method was selected to find 
the density of the Palmyra fiber. The weighed quantity of fiber was completely engrossed in water and the volumetric displacement was observed. The weight to volume ratio yielded the densityvalue.

\subsubsection{TensileStrength}

The cleaned and dried single fiber is mounted along the centerline of a slotted paper window as shown in Fig 2.6. The ends of the paper window are clamped in the grips of the Intron-testing machine with gauge length of $50 \mathrm{~mm}$ and its mid-section is cut off during loading. The load is applied with the crosshead speed of $1 \mathrm{~mm} / \mathrm{min}$ till the fiber brakes and the load deflection curve is recorded. Fibers are not uniform and it varies from $70 \mathrm{MPa}$ to $250 \mathrm{MPa}$. Variation in fiber strength is observed even in the same diameter fiber.

The fiber sample 3 with diameter of $0.5 \mathrm{~mm}$ has the maximum strength of $97.73 \mathrm{MPa}$, where the fiber sample 1 with diameter of $.03 \mathrm{~mm}$ has the strength of $118.25 \mathrm{MPa}$. From this it is observed that the strength is not proportional to the diameter. The modulus is also in the range of $2.5 \mathrm{GPa}$ to $10 \mathrm{GPa}$. The $\%$ of elongation varies between 5 and 3 . Strength of the fibers depends mainly on the fibrillar structure, micro fibrillar angle and the cellulose content.

The tensile test specimens were prepared according to ASTMD 638. For testing the specimen was seated in the grips of the Instron universal tester with 10 mm gauge length. The stress strain curves plotted during the test for the determination of ultimate tensile strength and elastic modulus. From the stressstrain curve, a straight line was tired and from the slope of the line the Young's modulus or elastic modulus was determined. Average of two tests results were taken.

\subsubsection{WaxContent}

The wax content was calculated with the help of sox lot apparatus. Petroleum benzene liquid was heated to $70^{\circ} \mathrm{C}$ and one gram of Palmyra fiber was immersed in the liquid. The 1hour reflux time was provided and the fiber sample was dried. After aeration the fiber, it was scale and weight difference fixed the wax content.

\subsubsection{MoistureContent}

The weighed quantity of Palmyra fiber was placed in an oven at the temperature range of $105 \pm 2{ }^{\circ} \mathrm{C}$ for 4 hour. The stress strain curves plotted during the test for the determination of ultimate tensile strength and elastic modulus. The weight of the fiber taken from the oven was deliberate and the difference in weight accounts for the moisture content present in thefiber

\subsubsection{CelluloseContent}

The weighed quantity of Palmyra fiber was immersed in a mixture of sodium chloride $1.72 \%$, and three drops of sulfuric acid in water. One hour soaked time was provided. Then the excess fluid was taken away by suction process and ammonia was added. The percentage of cellulose was noted by the ratio of the residue weight to the dry sample weight.

\subsection{Composite Fabrication}

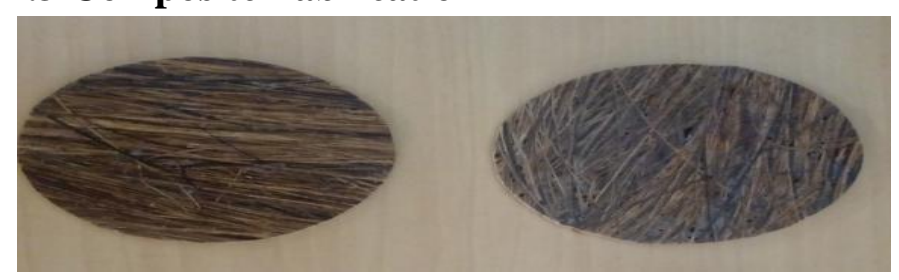

Fig.2 Fabricated composite materials

Fabricated Composite Materials as shown in figure Composite plates are prepared with mixer of epoxy and Palmyra fiber. The weighted amounts of untreated fiber were taken, and cleaned the dust from fiber. The fiber cut for different length, $25 \mathrm{~mm}$, and $27 \mathrm{~mm}$. The epoxy resin act as a bonding material of the composite plate. Based on The rule of mixture the fiber and resin were mixed. Earlier defined the best fraction 0.4 to 0.6 is mainly suites for composite material.

\section{RESULTS ANDDISCUSSION}

The Palmyra fiber reinforced composite was fabricated and sound absorption test explored on it. The results and its graph were mentioned below.

\subsection{Tensile Strength-}


Table.1 Tensile strength and elongation of Table 2. Fiber length and diameter

Palmyrafiber

\begin{tabular}{|c|c|c|c|c|}
\hline Sl. No. & $\begin{array}{c}\text { J0M } \\
\text { pa }\end{array}$ & $\begin{array}{c}\mathbf{F}_{\mathbf{H}} \\
\mathbf{N}\end{array}$ & $\begin{array}{c}\varepsilon_{H} \\
\%\end{array}$ & $\mathbf{F}_{\mathbf{B}} \mathbf{N}$ \\
\hline 1 & 322 & 9.31 & 2.60 & 9.16 \\
\hline 2 & 240 & 9.87 & 5.80 & 7.90 \\
\hline 3 & 437 & 6.49 & 0.55 & 5.18 \\
\hline 4 & 275 & 9.43 & 6.00 & 7.53 \\
\hline 5 & 1030 & 13.8 & 0.51 & 11.0 \\
\hline 6 & 464 & 14.9 & 3.60 & 14.8 \\
\hline 7 & 224 & 10.2 & 4.00 & 10.2 \\
\hline 8 & 361 & 13.8 & 4.60 & 13.8 \\
\hline 9 & 386 & 13.0 & 3.60 & 10.4 \\
\hline 10 & 227 & 11.5 & 4.70 & 11.5 \\
\hline 11 & 495 & 13.8 & 2.80 & 11.0 \\
\hline 12 & 189 & 7.86 & 9.60 & 7.84 \\
\hline 13 & 485 & 13.6 & 1.80 & 10.9 \\
\hline 14 & 474 & 14.4 & 5.80 & 14.2 \\
\hline 15 & 749 & 13.5 & 2.20 & 12.8 \\
\hline 16 & 609 & 12.7 & 2.00 & 12.7 \\
\hline 17 & 216 & 5.98 & 1.50 & 4.78 \\
\hline 18 & 691 & 14.0 & 0.80 & 13.8 \\
\hline 19 & 271 & 9.01 & 2.10 & 9.01 \\
\hline 20 & 287 & 8.55 & 1.50 & 8.51 \\
\hline
\end{tabular}

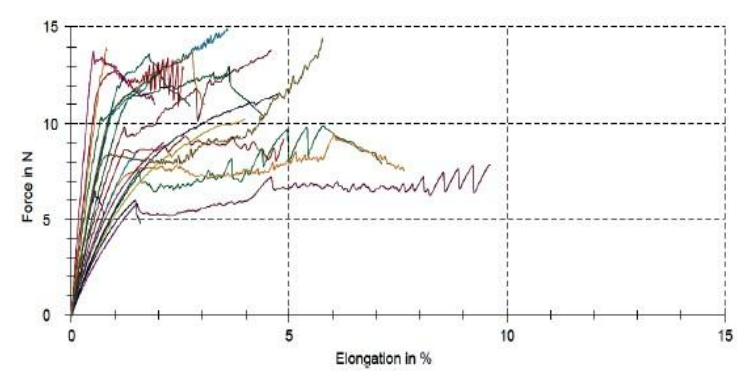

Fig.3 Graphs between force (F) and elongation (EH)

\subsection{Fiber Length andDiameter}

The Diameter and Length of the Palmyra fiber as shown in table 2. The diameter and length of palmyra fiber compared to other is more.

\begin{tabular}{|l|l|l|l|l|}
\hline \multirow{2}{*}{ Sl. No. } & \multicolumn{3}{|l|}{ Fiber Diameter in mm } & $\begin{array}{l}\text { Fiber } \\
\text { Length } \\
\end{array}$ \\
\cline { 2 - 5 } Tip & Middle & Bottom & $(\mathbf{m m})$ \\
\hline 1. & 0.48 & 0.53 & 0.51 & 535 \\
\hline 2. & 0.45 & 0.60 & 0.63 & 530 \\
\hline 3. & 0.56 & 0.65 & 0.75 & 510 \\
\hline 4. & 0.50 & 0.55 & 0.70 & 470 \\
\hline 5. & 0.48 & 0.53 & 0.53 & 470 \\
\hline Average & $\mathbf{0 . 4 9}$ & $\mathbf{0 . 5 7}$ & $\mathbf{0 . 6 2}$ & $\mathbf{5 0 3}$ \\
\hline
\end{tabular}

\subsection{Chemical Properties of PalmyraFiber}

Table 3.Fiber chemical composition Table 5. Sound absorption value (sample2)

\begin{tabular}{|l|l|}
\hline $\begin{array}{l}\text { Fiber Chemical Composition } \\
\text { Testing }\end{array}$ & \\
\hline Cellulose content, \% & 69.3 \\
\hline Lignin content, \% & 22.62 \\
\hline Wax content, \% & 0.24 \\
\hline Ash content, \% & 4.53 \\
\hline Moisture content, \% & 8.15 \\
\hline Density, g/cc & 1.4012 \\
\hline
\end{tabular}

\subsection{Sound Absorption Test onSFC}

Sound absorption coefficient was found for Composite Material with the volume fraction of 4060 and 35-65 for various frequencies. From the tabulated values, the average noise reduction coefficient was found that shown in the table 6.4 and table 6.5. In that report sample 1 represents the Composite Material with volume fraction of 4060 and sample 2 represents the Composite Material with volume fraction of 35-65. 
Table 4. Sound absorption value (sample1)

\begin{tabular}{|c|c|c|}
\hline Sl. No. & $\begin{array}{c}\text { Frequency } \\
\text { (Hz) }\end{array}$ & $\begin{array}{c}\text { Sound } \\
\text { Absorption }\end{array}$ \\
\hline 1 & 63.00 & 0.08 \\
\hline 2 & 80.00 & 0.03 \\
\hline 3 & 100.00 & 0.04 \\
\hline 4 & 125.00 & 0.00 \\
\hline 5 & 160.00 & 0.03 \\
\hline 6 & 200.00 & 0.04 \\
\hline 7 & 250.00 & 0.04 \\
\hline 8 & 315.00 & 0.04 \\
\hline 9 & 400.00 & 0.05 \\
\hline 10 & 500.00 & 0.07 \\
\hline 11 & 630.00 & 0.06 \\
\hline 12 & 800.00 & 0.08 \\
\hline 13 & 1000.00 & 0.16 \\
\hline 14 & 1250.00 & 0.53 \\
\hline 15 & 1600.00 & 0.47 \\
\hline 16 & 2000.00 & 0.21 \\
\hline 17 & 2500.00 & 0.16 \\
\hline 18 & 3150.00 & 0.22 \\
\hline 19 & 4000.00 & 0.28 \\
\hline 20 & 5000.00 & 0.25 \\
\hline 21 & 6300.00 & 0.46 \\
\hline Average & 1448.714 & 0.157 \\
\hline
\end{tabular}

Table 5. Sound absorption value (sample 2)

\begin{tabular}{|c|c|c|}
\hline Sl. No. & $\begin{array}{l}\text { Frequency } \\
\text { (Hz) }\end{array}$ & $\begin{array}{c}\text { Sound } \\
\text { Absorption }\end{array}$ \\
\hline 1 & 63.00 & 0.07 \\
\hline 2 & 80.00 & 0.04 \\
\hline 3 & 100.00 & 0.03 \\
\hline 4 & 125.00 & 0.01 \\
\hline 5 & 160.00 & 0.03 \\
\hline 6 & 200.00 & 0.04 \\
\hline 7 & 250.00 & 0.04 \\
\hline 8 & 315.00 & 0.05 \\
\hline 9 & 400.00 & 0.07 \\
\hline 10 & 500.00 & 0.13 \\
\hline 11 & 630.00 & 0.12 \\
\hline 12 & 800.00 & 0.17 \\
\hline 13 & 1000.00 & 0.51 \\
\hline 14 & 1250.00 & 0.17 \\
\hline 15 & 1600.00 & 0.24 \\
\hline 16 & 2000.00 & 0.57 \\
\hline 17 & 2500.00 & 0.70 \\
\hline 18 & 3150.00 & 0.30 \\
\hline 19 & 4000.00 & 0.17 \\
\hline 20 & 5000.00 & 0.24 \\
\hline 21 & 6300.00 & 0.83 \\
\hline Average & 1448.714 & 0.2157 \\
\hline
\end{tabular}

Table 6 Noise reduction coefficient

Sample1

\begin{tabular}{|c|c|}
\hline \multicolumn{2}{|c|}{ NR } \\
\hline 250 & 0.04 \\
\hline 500 & 0.07 \\
\hline 1000 & 0.16 \\
\hline 2000 & 0.521 \\
\hline Average & $\mathbf{0 . 1 2}$ \\
\hline
\end{tabular}

Sample2

\begin{tabular}{|c|c|}
\hline \multicolumn{2}{|c|}{ NRC } \\
\hline 250 & 0.04 \\
\hline 500 & 0.13 \\
\hline 1000 & 0.51 \\
\hline 2000 & 0.57 \\
\hline Average & $\mathbf{0 . 3 1 2 5}$ \\
\hline
\end{tabular}




\section{CONCLUSION}

In this project, an attempt was made to study the physical, chemical properties of Palmyra fiber and sound absorption test on Palmyra fiber reinforced epoxy composite with the volume fraction of 40-60 and 35-65. From the test report of sound absorption test on composite material, it was observed that the sound absorption capacity of Palmyra fiber is very impressive. Particularly, composite material with volume fraction of 40-60 much better than the composite material with 35-65. So, the Palmyra fiber reinforced epoxy composite with the volume fraction of 40-60 can be suggested for the sound absorbing application.

\section{REFERENCES}

1. Abdul Khalil, H.P.S., Jawaid, M., Bhat, A.H., and Abu Baker, A. (2011) Impact Properties of Natural Fiber Hybrid Reinforced Epoxy Composites, Advanced Material Research Vol.264, pp.688-693.

2. Boopathi, L, Sampath, P.S., Mylsamy, K. (2012) Influence of Fiber Length in the Wear Behaviour of Borassus Fruit Fiber Reinforced Epoxy Composites, Int. Jou. of Engineering Science and Technology Vol.4, pp. 4119-4129

3. Malkapuram Ramakrishna, Kumar Vive. (2009) Recent development in natural fiber reinforced polypropylene composites, ReinfPlast J., Composite Vol.28, pp. 11691170.[4] Murali Mohan Rao K, MohanaRao K.(2007) Extraction and tensile properties of natural fibers: Vakka, date and bamboo, Composite Structure Vol.77, pp. 288-295.

4. Khristova, P.O., Kordsachia and T. Khider, 2005. Analysis of coir fiber acoustical characteristics. Alkaline pulping with additives of date palm rachis Applied Acoustics, 72:35-42.

5. Riahi, K., A. Mammoub and B. Thayer, 2009. 61: 173-82. Date-palm fibers media filters as a potential 13. Delany,

6. M.E. and E.N. Bazley, 1970. Acoustical technology for tertiary domestic wastewater properties of fibrous absorbent materials. Applied treatment. Journal of Hazardous Materials, Acoustics, 3: 105116.

7. YounEung Lee, Chang WhanJoo, 2004. Sound Absorption Properties of Thermally BondedNonwovens 